\title{
On Application of Output-Driven Hypothesis on College English Teaching*
}

\author{
WANG Li \\ Qingdao University of Science and Technology, Qingdao, China
}

\begin{abstract}
This paper discusses how college English teaching can be carried out based on the output-driven hypothesis. It consists of three sections. Section one briefly describes the views of the output-driven hypothesis with relevant theoretical explanations. Section two further illustrates how such teaching practice can be conducted in terms of the teaching objectives, teaching procedures, and methods, and assessment focuses. Section three points out the potential challenges faced by university English teachers when the hypothesis is tested.
\end{abstract}

Keywords: output-driven hypothesis, college English teaching, teaching objectives, teaching procedures and methods, assessment

\section{Introduction to the Output-Driven Hypoghesis}

Output-driven hypothesis in this paper mainly directs at those who have received professional education of foreign language with certain language basis. It includes: (1) As for teaching process, output can better motivate foreign language learning than input, not only facilitating the application of language knowledge received but also inspiring the students' desire to learn new language knowledge. (2) As for teaching objective, it more suits for the social demand to cultivate such expressive language skills like speaking, writing, and translation, thus they are considered to be the dominant assess objective while such receptive skills like listening and reading are considered to be recessive objective.

Since 1980s, Krashen (1985) put forward input hypothesis, Swain (1985) brought forward output hypothesis, and Long (1983) put forward interactive hypothesis. There are some similarities between the output-driven hypothesis here which was put forward by WEN Qiu-fang in 2008 and the output hypothesis brought forward by Swain. The similarities are as follows: to improve the fluency and atomization of language; to try the truth of hypothesis; to strengthen the awareness of language and find out the gap between what the learners think and what they can; to cultivate the ability to reflect on the mealanguage. However, there are still some differences.

Firstly, their starting points are different. The output hypothesis mainly discusses the theory, defining the different effects of output and input on the second language acquisition process while the output-driven

\footnotetext{
* Acknowledgements: This paper is the final result of the research project the author hosts "College English Teaching Mode Innovation Based on the Output-Driven Hypothesis" that is supported by "College Teaching Reform and Research Funds for Qingdao University of Science and Technology" in 2014.

WANG Li, lecturer, master, Institute of Foreign Languages, Qingdao University of Science and Technology.
} 
hypothesis mainly focuses on the second language teaching efficiency, discussing how the foreign language teaching better serves for the further development of the students.

Secondly, the objectives they try to challenge are different. What Swain tries to challenge is the input hypothesis put forward by Krashen. Krashen (1985) holds an opinion that second language acquisition depends on the quantity and quality of the input. The output is just the by-product of input, without any direct help to acquire language. While what the output-driven hypothesis tries to challenge is the teaching order as well as the teaching objective to keep the balance among listening, speaking, writing, and translation. It mainly holds that the output is the staring point and the ultimate objective of teaching which can help apply what the learners have learned in the past to the real situation, thus promoting the students to learn new language knowledge more actively and getting a better teaching effect.

\section{The Application of Output-Driven Hypothesis on College English Teaching}

Tyler, the herald of curricula theory in America (1949) put forward the four elements of curricula framework, they are respectively objective, presentation, the way of presentation, and assessment. This paper mainly illustrates the application of output-driven hypothesis on college English teaching based on the four elements put forward by Tyler.

\section{Teaching Objective}

In accordance with The Teaching Requirements of College English Course issued by Higher Education Department of Education Ministry in 2007, college English course is supposed to improve the students' ability to apply English to the real situation. In addition to it, it also requires to improve the students' self-study ability, trans-cultural communication ability, and comprehensive cultural manner. Based on the teaching objective of applying English to the real situation, the output-driven hypothesis puts forward two important points. Firstly, in order to be used to the further development of students' career, college English course focuses on the skills of speaking, writing, interpretation, and translation instead of the skills of reading and listening because they are just the basis of output skills rather than teaching objective to be checked. Secondly, the students are offered more choices. They can choose to develop different output skills in a balanced way according to their strong traits and goals in the future. Based on the idea of "learning what students need to learn according to what they can do" required by college English teaching, college students should be given more opportunities to choose their English learning objectives and courses.

\section{Teaching Procedures and Methods}

Teachers' tasks. (1) Design real-world output tasks suited for students' language level. Teachers should design different tasks before having class, like oral tasks, writing tasks, interpretation, or translation tasks, or even the comprehensive tasks involved in multi-output activities. All these tasks should satisfy two basic requirements: One is to ensure that the communication should be the real-world one; the other is to ensure that the difficulty of the language should be suitable. The real-world communication means the designed tasks should be possibly met with in daily life. For example, there are two tasks. One is to explain what "Chinese dreams" means and what "scientific outlook on development" is to foreigners in English. The other is to make a speech on how to respect the environment in English. Obviously, the former is much more like the real-world communication than 
the latter. While the suitable difficulty means the English vocabularies and sentences needed to finish the tasks should be suitable for what the students have learned lately. That is to say, it requires the teachers not only to be familiar with what the students learned at middle school but also to get the information of the students' language level now. As for the tasks designed by the teachers, if it only takes two or four classes to finish, it is considered to be "task"; if it takes eight or more classes to finish, it is called "project".

(2) Supply new input materials. The main purpose of supplying new materials is to help the students supplement the language knowledge needed to finish the output tasks. Therefore, whether the input materials are suitable decides a lot. The more suitable the materials are for the tasks, the more active the students become, the more efficient the absorption of the new knowledge is. As for the input materials, it can be either one passage or more than one; it can be either the reading materials or video and listening materials. What should be noted here is that the input materials should be chosen by the teachers according to different types of the tasks. If what the students have to finish is not a task but a project that needs a longer time, the teachers should divide it into several tasks and supply input materials step by step in accordance with the project progress, thus the students will not feel confused and do not know what they should do in front of too many materials.

(3) Offer proper help when the students finish the output tasks. The teachers can offer students help in different ways when they finish the output tasks. For example, the teachers can spend time discussing the difficulties the students may encounter when they are doing the output activities, including the language and organization. In addition to it, the teachers can know about how the students prepare for the output tasks and its results as well as review the PPT (PowerPoint) made by the students. During the process the teachers offer help, they had better play the role of scaffold. As for the traditional teaching, it usually follows the principle of "practice makes perfect" when educating the students how to form a better output ability, merely offering students the chances to practice and requiring the students to repeatedly practice. The basic teaching process is as follows: The teachers arrange assignments and homework, then the students practice and prepare for it; the students present it and the teachers evaluate it. The teachers' role played during the teaching process is more like a "judge" who is responsible for evaluating the students' performance; being lack of the part, the teachers tutor the students what to do. In contrast, as for the output-driven teaching, when preparing for the class, the teachers should arrange for the detailed steps and content in order to ensure the efficiency when they making the supervision and evaluation, making sure that the students' ability will be increasingly improved.

(4) Provide pointed comment. Nowadays, there is a serious problem existing in the teaching, that is, the comment on the students' oral tasks made by the teachers is empty, neglecting the listeners' performance. In addition, as for the comment on the written tasks, the teachers usually focus on the simple mistakes in the language itself, neglecting to correct the exactness of semantics expression and the logicality of content organization. The factors causing the problems mentioned above are various. Take the comment on the oral tasks as an example, the main reason for it is that the teachers do not know what the students are going to present in advance, lacking the preparation beforehand, thus making it difficult to make a proper comment on what the students present, losing control of what the listeners may react. Therefore, the teachers are required to get known what the students will present in advance. Even if there is some trouble communicating face to face between teachers and students, the teachers should require the students to send their oral presentation in written to the teachers' mailbox in order to make sure that the teachers will have enough time to think how to make a proper 
comment and design the tasks that can appeal the listeners to take an active and efficient part in. Some teachers usually ask the listeners to make a score on the presentation made by the students in order to help them concentrate on the oral presentation. However, the problem lies in the fact that the score itself may not necessarily make the point because the score could still be made when the listeners are distracted. Similarly, the listeners cannot keep concentrated from the beginning to the ending when they are required to make a comment on the oral presentation. The teachers are recommended to design a task which is closely related with the oral presentation they are going to listen. The more detailed the task is, the better the effect will be. For instance, the listeners can be required to note down three key points involved in the oral presentation when listening.

Students' tasks. (1) Try to finish the output tasks. It should be noted that what emphasized here is not whether the students can finish it successfully or not but whether the students try to finish the output tasks or not. If the students can point out the difficulties they have encountered during the output process and list their weakness in language knowledge, their tasks can be considered to be successful.

(2) Learn and search the new language materials. The students are required to find out how to solve the problems from the materials offered by the teachers in accordance with the different requirements of the output tasks. If the offered materials are not sufficient enough to solve all problems, the students can write them down. There are two solutions to it: One is to ask for the teachers' help when the students can talk with the teachers face to face next time; the other is to find out the books materials and search the Internet, or to discuss it with the other classmates.

(3) Prepare for the language output activities. Just like what is mentioned above, some are simple tasks while some are projects involved in a series of tasks; some are individual tasks while some are pairs or groups tasks. Aiming at the different types and scales of the tasks as well as the numbers of the participants, the way of preparation should be different. Once it requires more than two students to finish the task, a coordinator is needed. What the coordinator does is to be responsible for dividing and supervising the whole output task, making sure that the work will be equally assigned and the task will be finished smoothly. Generally speaking, there are three steps to prepare for the oral task: organize the content; make PPT; rehearse it. As the written task, the preparation includes: lay out the outline; write the first draft; revise it over again.

(4) Present and enjoy the output achievement. The students should not only know how to present their own output achievements but also learn from the others'. If the preparation is well done, and the presenters, listeners, and teachers can make their respective contributions to it during the presentation, a great power will be formed, and eventually the final effect will be greatly improved.

The teaching principle we advocate in the teacher-student activities is that the teachers guide the students while the students are centered. That is to say, all activities ask for both the teachers' guide and the students' active participation because both of them will decide the teaching effect. The teaching principle of "students centered" which is popular since the 21 st century weakens to some extent the teachers' roles in the class. Admittedly, the class teaching needs to serve for the students, but it does not mean to marginalize the teachers' roles. After all, the teachers can master the whole knowledge system and know about the key points and difficult points after receiving the specialized training, so they are supposed to control the teaching process, adjust the teaching strategies, and offer students proper help, making the teaching effect best. 


\section{Assessment Focus}

The assessment focus should be adjusted after the output-driven hypothesis is carried out.

Assess the ability to apply the language instead of the language knowledge. Since what the output-driven hypothesis evaluates is the students' ability to apply the language, as a result, the choices and cloze exercises which are used to test the grammar and vocabularies in the past are not allowed to appear in the papers. Instead, what is evaluated is whether the students can write the abstract after reading the English books and whether the students can make a piece of news in Chinese after editing and translating several pieces of news with the similar topic on newspapers in the foreign countries and so on because these tasks may be encountered in the future jobs.

Make sure of the reliability of the assessment on the subjective exercises. In order to improve the reliability of the evaluation on the subjective exercises, different types of evaluation should use different ways. The teachers group should work together to discuss and make the evaluation standard in order to improve the feasibility of it. As for the evaluation on the students' daily performance, the teachers should make the students know the content of the evaluation standard.

\section{Challenges of Implementing the Output-Driven Hypothesis}

The challenges of implementing the output-driven hypothesis come from two aspects.

(1) Reform the traditional concept of teaching books. Compared with the traditional teaching progress, when implementing the output-driven hypothesis, the teachers should design the output tasks firstly, and then offer students related materials according to the difficulties the students may encounter when finishing the input tasks. In such a way can shorten the distance between input learning and output applying. Of course, the teachers should also encourage the students to find out the supplement materials from the library or search it online.

(2) Break the teaching mode based on the text. The traditional college English teaching usually relies on the textbook. But the output-driven hypothesis requires the teachers to create the new teaching process according to the students' English level.

\section{Conclusion}

This paper illustrates the feasibility of implementing the output-driven hypothesis and analyses the difficulties both the teachers and students may encounter when implementing the output-driven hypothesis. As long as we work together and make continuous practice and innovation, we can find out more effective English teaching ways which are suitable for the current situation in our country.

\section{References}

Higher Education Department of Education Ministry. (2007). The teaching requirements of college English course. Beijing: Foreign Language Teaching and Research Press.

Krashen, S. (1985). The input hypothesis: Issue and implications. London: Longman.

Long, M. (1983). Native speaker/non-native speaker conversation and the negotiation of comprehensible input. Applied Linguistics, 4(2), 126-141.

Swain, M. (1985). Communicative competence: Some roles of comprehensible input and comprehensible output in its development. In S. Gass \& C. Madden (Eds.), Input in second language acquisition. Rowley, MA: Newbury House.

Tyler, R. W. (1949). Basic principles of curriculum and instruction. Chicago: The University of Chicago Press. 
WEN, Q. F. (2008). The output-driven hypothesis and the reform on English skills course. Foreign Language World, 2.

WEN, Q. F. (2012). The challenges and strategies faced by college English: From the view of curriculum theory. Foreign Language

Teaching and Research, 2.

ZHAO, J. N. (2012). On the new mode of oral English based on the output-driven hypothesis. Foreign Language Research, 10. 